\title{
Volcano Deformation Monitoring Using GPS
}

\author{
Volker Janssen
}

\begin{abstract}
Volcanic eruptions are often very destructive events, having a massive impact on the natural and human environment. In order to mitigate the effect of volcanic hazards such as pyroclastic flows, lahars and tsunamis it is necessary to closely monitor volcanoes. Ground surface deformation is recognised as a reliable indicator of an impending eruption and can give clues to magmatic processes at depth. This paper gives a brief overview of the techniques employed for volcano deformation monitoring and then reviews advances in the use of GPS for this purpose. Recommendations on the ideal GPS system infrastructure are made.
\end{abstract}

\author{
Volker Janssen \\ Centre for Spatial Information Science \\ School of Geography and Environmental Studies \\ University of Tasmania \\ Private Bag 76 \\ Hobart TAS 7001 \\ Australia \\ Volker.Janssen@utas.edu.au
}




\section{INTRODUCTION}

Volcanoes are an awesome display of Nature's power. In addition, volcanic explosions are often very destructive events, having a massive impact on the natural and human environment. It is therefore necessary to closely monitor volcanoes in order to mitigate the hazards arising from an eruption. The successful prediction of the extremely explosive 1991 eruption of Mt. Pinatubo in the Philippines (the second largest eruption in the $20^{\text {th }}$ century) saved many thousands of lives, as 60,000 people had been evacuated on the day prior to the eruption (Newhall \& Punongbayan 1996). Ground surface deformation can give clues to magmatic processes at depth, and is a reliable indicator of an impending eruption. However, each volcano is unique and has its own characteristics and behaviour. To really understand a volcano, the scientist has to essentially 'marry' the volcano. This humorous statement illustrates the need for long-term monitoring to study the varying 'moods' of these beautiful, but also hazardous, giants in order to detect as early as possible any deviations from their normal behaviour. The data obtained can contribute to volcanic hazard mitigation and disaster risk management by providing timely ground deformation information to volcanologists.

\section{VOLCANO DEFORMATION MONITORING}

When and where will the volcano erupt? This is the essential question scientists concerned with volcano monitoring have to answer, as precisely as possible. Several different techniques can be applied to study volcanoes, including seismic, micro-gravitational, geomagnetic, geodetic, geochemical, geothermal, hydrologic, remote sensing and visual observations.

Ground deformation due to volcanic magma intrusion is recognised as an important precursor of eruptive activity at a volcano. Before an eruption occurs, the ground surface generally expands due to the pressure increase within the shallow magma chamber caused by upward magmatic movements several kilometres below the volcano. The trend is reversed after magma is released from the chamber causing deflation of the flanks of the volcano (Fig. 1). The pattern and rate of surface displacements reveal the depth and the rate of pressure increase within the subterranean magma chamber (Dvorak \& Dzurisin 1997), giving important information about the state of the volcano. As ground deformation tends to precede eruptions by periods of hours to months, geodetic monitoring is an effective tool for hazard mitigation.
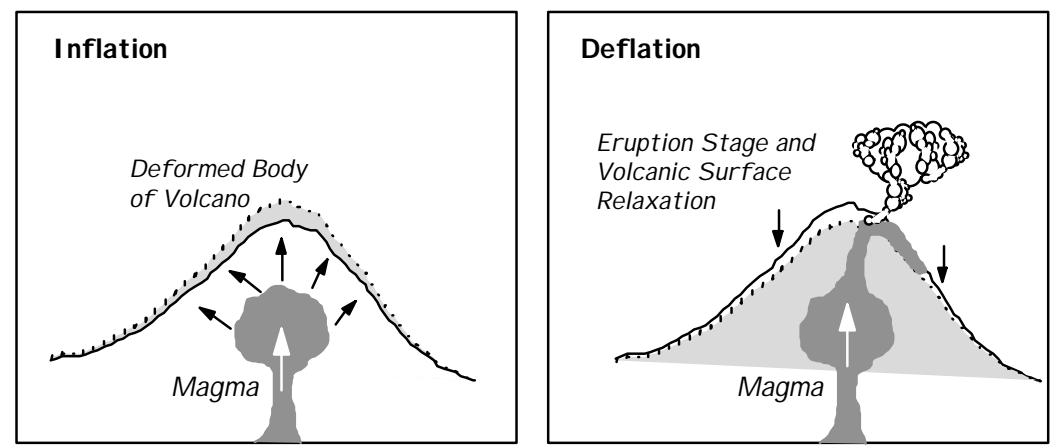

Figure 1. Ground deformation caused by magmatic activity (Abidin 1998)

Ground deformation monitoring techniques for volcanic environments have developed from precise spirit levelling to electronic distance measuring (EDM) techniques, and more recently to the use of InSAR, and campaign-style or continuous GPS surveys. These techniques can be classified as being either episodic or continuous. Episodic techniques include angle and distance measurements, levelling, InSAR and repeated GPS surveys. Instrumentation used for continuous monitoring includes tiltmeters, strain meters and permanent GPS networks.

Perhaps the first documented ground deformation associated with a volcanic event was the work reported by Omori (1914). His investigations indicated vertical ground displacements on the Mt. Usu volcano in Japan of up to $2 \mathrm{~m}$ when conducting precise levelling surveys before and after the eruption of 1910 . A $100 \mathrm{~m}$ upheaval of the ground surface was also recorded close to the crater at the time of eruption.

Using elastic theory and data from several case studies, Mogi (1958) developed a mathematical model in order to determine the position and depth of a magma source based on ground deformation measurements and their locations. He assumed that the ground deformation is caused by a spherical source (magma chamber) located below a volcano edifice, which exerts hydrostatic pressure upward to the ground surface. Mogi (1958) proposed that the earth's crust behaves elastically at the time of eruption while, during the long period of deformation after the eruption, the crust behaves as a visco-elastic medium. This simple model has proven to be very effective and is still widely being used today to estimate the location of the magma source. 
From the 1960s through to the 1980s, traditional surveying techniques were used for ground deformation monitoring. Generally these networks consisted of spirit levelling runs to detect vertical movements, and triangulation networks in order to determine horizontal displacements.

The introduction of electronic distance measuring (EDM) equipment enabled relatively long distances to be measured quickly and precisely. Suganda (1993) reported a $2 \mathrm{~m}$ change in the horizontal distance between points spanning the crater of the notoriously active Mt. Merapi in Indonesia from four campaigns of EDM measurements conducted between 1988 and 1992. At Mt. Unzen (Japan) EDM observations showed that the growing lava dome was expanding at a rate of $70-80 \mathrm{~cm}$ per hour over a few days preceding the eruptive event of May 24, 1991 (BGVN 1991).

Combining several geodetic techniques further improved ground deformation monitoring. Bonasia \& Pingue (1981) reported on a system on Mt. Vesuvius in Italy comprising a levelling network, EDM measurements, tilt measurements, and the analysis of apparent zenith distances of the crater bottom from a fixed point located on the crater rim. Blick et al. (1989) described a network combining angle measurements, EDM measurements and tilt measurements on Mt. Erebus in Antarctica. Even repeated steel tape measurements across cracks in the ground can provide valuable information, as reported by Swanson et al. (1983), who successfully used this technique to record episodes of accelerating growth of the Mount St. Helens lava dome between 1980 and 1982. These measurements, in conjunction with data gathered by other means, led to the prediction of 13 eruptions during this period. A comprehensive review of the various ground deformation monitoring techniques used by the staff of the Cascades Volcano Observatory for the period 1980-1990 can be found in Ewert \& Swanson (1992).

With advances in GPS techniques in the 1980s it was quickly realised that GPS is well suited to monitor deformation caused by tectonic motion, ground subsidence and volcanic activity. The GPS techniques will be discussed further in the next section.

In recent years, interferometric synthetic aperture radar (InSAR) techniques have increasingly been used to map the topography of volcanoes and detect ground deformation. InSAR is capable of producing a detailed image of the surface displacement field, rather than measurements at only a small number of points - a huge advantage over conventional techniques. Using ERS-1 SAR images taken between 1992 and 1993, Briole et al. (1997) detected a deflation "moderate in size and amplitude" associated with the 1986-87 and 1989 lava flows on Mt. Etna, Italy. Around the vent of the New Trident volcano in Alaska, a 7-9cm uplift was observed over a 2-year period by Lu et al. (1997). Other case studies were reported by Rosen et al. (1996), Amelung et al. (2000), Lu et al. (2003) and Furuya (2004). Due to its high degree of spatial coverage and completeness (spatial resolution of a few $10 \mathrm{~m}$ over an image size of $100 \mathrm{~km} \times 100 \mathrm{~km}$ ), its cost-effectiveness and ability to penetrate clouds, the use of InSAR is certainly a beneficial option in complex and inaccessible terrain. However, dense vegetation and snow cover can preclude the use of InSAR as a volcano monitoring tool. Furthermore, these techniques are dependent on the time span between image acquisitions, which also influences the coherence of the images. Hence, at present it is often not possible to detect short-term deformation. In the near future, an increase in the number of satellites equipped with SAR will improve the situation.

\section{VOLCANO DEFORMATION MONITORING USING GPS}

The GPS technology is well suited for volcano deformation monitoring because GPS measurements can provide three-dimensional positions, potentially at centimetre-level accuracy, independent of weather conditions, 24 hours per day. In addition, there is no requirement for intervisibility between stations within a GPS network, and measurements can be made over relatively long distances. GPS has therefore many advantages over conventional geodetic techniques, considering that most of the world's volcanoes reach high altitudes and are prone to frequent cloud cover. Furthermore, once a GPS network is installed, no human presence is needed at a potentially dangerous volcanic locale. By repeatedly measuring the same baseline vector to an accuracy commensurate to (and preferably much higher than) the expected baseline component changes due to deformation, the rate of change in the baseline components can be reliably determined.

Probably the first GPS survey to be carried out in a volcanic area was undertaken in Iceland during 1986 (Foulger et al. 1987). A little later, Sigmundsson et al. (1992) detected ground deformation associated with a fissure eruption at the Hekla volcano in Iceland. Marshall et al. (1997) observed ground inflation caused by dike opening at the Long Valley Caldera, California from five annual GPS campaigns between 1990 and 1994. Ground deformation caused by magma intrusion and lava discharge was detected and reported by Nishi et al. (1999) after a series of GPS campaigns were conducted on Mt. Unzen in Japan over 5 years. The study revealed ground inflation before the lava dome extrusion took place. This was followed by deflation, as the lava dome grew and created pyroclastic flows caused by frequent collapses of the lava dome. The detected ground 
deformation (inflation and deflation) was successfully explained by a pressure source located about $6 \mathrm{~km}$ west of the active crater at a depth of $11 \mathrm{~km}$, determined using the Mogi model. At the Soufriere Hills volcano, Montserrat, a series of GPS campaigns conducted fortnightly over a period of one year revealed displacements radially symmetrical around the growing lava dome. It was concluded that the centre of pressure causing the observed ground deformation was within the dome itself rather than within a magma chamber at any significant depth beneath the volcano or within a large conduit leading to the surface (Shepherd et al. 1998).

The Institute of Technology Bandung conducts regular campaigns on several volcanoes in Indonesia (Abidin et al. 1998, 2004, 2006). Local GPS campaigns are also used to monitor dome growth in conjunction with precise levelling lines and/or EDM distance measurements (e.g. Matsushima \& Takagi 2000, Nunnari \& Puglisi 1994, Puglisi et al. 2001). All of these surveys, however, are conducted in a campaign-style mode, i.e. short measurement surveys separated by long time periods, and therefore give no indication of the rate of ground movement between the campaigns. This might be suitable for quiescent volcanoes, but is certainly not sufficient for volcanoes exhibiting a higher degree of activity. In addition, the stability of the monuments becomes an issue, as the geodynamic signal can be contaminated by systematic biases such as soil movement, centring errors of a tripod or theft/vandalism of the marks themselves. The cost of planning end executing a GPS campaign can become a much larger expense than the cost of the instruments themselves, and logistical problems often cause delays in data processing.

Most of these disadvantages can be overcome by adopting a continuous GPS deformation monitoring approach. The setting-up of a continuous GPS infrastructure provides uninterrupted measurements of the displacement of volcano monitoring points. GPS is well suited to operate automatically in a remote environment powered by batteries and solar panels, with the logged data being transmitted to a central computing facility via a radio link.

One of the first continuous GPS networks was established in March 1988 on the Izu Peninsula in central Japan to support earthquake prediction research. Daily observations of this network led to the first GPS measurements of surface deformation as it occurred (Shimada et al. 1990). Their results showed that the distance between two benchmarks $10 \mathrm{~km}$ apart increased by $14.5 \mathrm{~cm}$ during the seismic activity. This was attributed to the opening of a magma-filled fracture, which indeed fed a new eruption of the Teisha sea-floor volcano located off the coast 10 days later.

Since then several networks of continuously operating GPS receivers have been installed at volcanoes around the world, e.g. at the Long Valley Caldera, California (Dixon et al. 1997), Soufriere Hills volcano, Montserrat (Mattioli et al. 1998), and Kilauea volcano, Hawaii (Owen et al. 2000a, 2000b). The development of an automatic GPS array for such small scale monitoring is an engineering and software challenge. A network of permanent GPS receivers must be deployed in an often inhospitable environment, in which they must operate reliably on a continuous basis. Power supply in remote locations becomes a big issue, with batteries and solar panels having to be used. The GPS observations must then be telemetered to a central computing facility where data processing occurs with minimum delay. Such local networks can be realised in different ways, based on a static or kinematic approach. Which system design is chosen usually depends on the expected amplitude and frequency of deformation, the terrain, available power sources and budget constraints.

\section{Continuous Static GPS Networks}

A local network of continuously operating GPS receivers is well suited to monitor relatively small areas around a volcano. One of the first such networks was established by the U.S. Geological Survey (USGS) on Augustine volcano, Alaska (Fig. 2). Three dual-frequency GPS receivers are used, and the baselines are measured on a weekly basis. The data are transmitted from the two remote stations on the flank and summit of the volcano to a base station for processing (USGS 2006a).

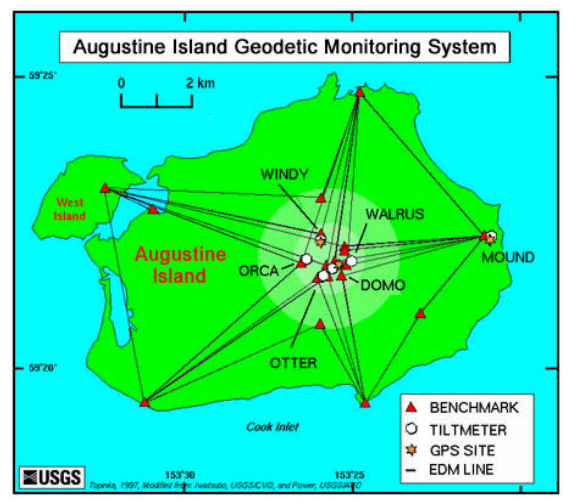

Figure 2. Volcano deformation monitoring network on Augustine Island (USGS 2006a) 
The USGS also operates 16 continuous GPS sites as part of a ground deformation network to monitor the Kilauea, Mauna Loa and Mauna Kea volcanoes in Hawaii (USGS 2006b). GPS data are sampled every 30 seconds and downloaded once a day to calculate one-day average positions. In addition, more than 100 other sites are surveyed intermittently during GPS campaigns. Figure 3 shows part of this network, the sites NUPM and KTPM spanning the east rift zone of Mauna Kilauea, about 6km from the Pu'u 'O'o vent. MLPM is located on the south-eastern flank of Mauna Loa, while MKPM is located on the summit of Mauna Kea. During a brief eruptive episode of the Kilauea volcano that began on January 30, 1997, the continuously recording GPS receivers measured significant ground deformation near the eruption site. As magma forced its way up into the rift beneath the Napau Crater, the two GPS sites located on either site of the east rift moved apart by $36 \mathrm{~cm}$ during the activity, and continued to move apart at a slower rate after the activity stopped on January 31 (Fig. 4). The results clearly showed that the relatively small eruption was associated with a much larger volume of magma that intruded into the rift zone and remained below ground. The eruption on Kilauea was preceded by 8 hours of rapid deflation of Kilauea's summit (Owen et al. 2000b).

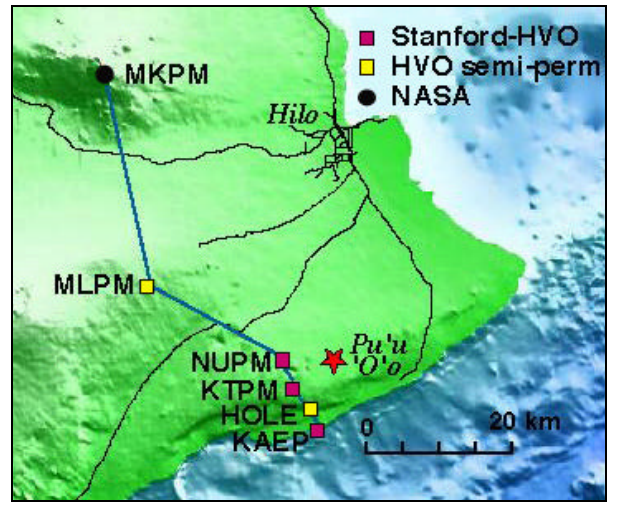

Figure 3. Map showing the location of several GPS receivers on Hawaii, adapted from USGS (2006b)

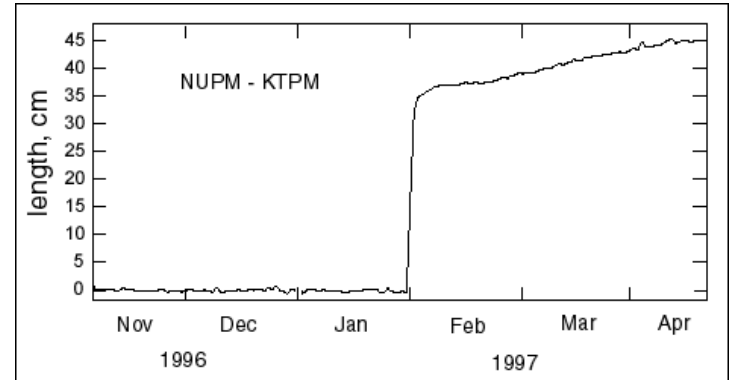

Figure 4. Increase in distance between the sites NUPM and KTPM during the eruptive event of January 30, 1997 (USGS 2006b)

A dense, continuous GPS network of about 20 sites was established to monitor ground deformation at the Iwate volcano in Japan. GPS data are collected at a sampling rate of 60 seconds and transferred to the computing facility at Tohoku University via phone line, cellular phone or radio link, depending on the site location. The data are analysed using the GAMIT software (King \& Bock 1995) and precise ephemerides to produce daily solutions. During a period of unrest in 1998, significant deformation of about 3-4cm horizontally and a $2 \mathrm{~cm}$ uplift were observed (Miura et al. 2000). The horizontal displacements showed a radial pattern pointing outward from the western flank of the volcano and displacement rates increased especially in the east-west components. It was estimated that the source of deformation was initially dike intrusion caused by a tensile fault located $5 \mathrm{~km}$ west of the summit at a depth of $3 \mathrm{~km}$. During the course of activity it then changed its nature to an isotropic pressure source according to the Mogi model, and migrated approximately $6 \mathrm{~km}$ further westward. Displacements due to an M6.1 earthquake that occurred on September 3, 1998, about 10km southwest of the summit were also detected. A fault model of the earthquake was determined based on GPS data and showed good agreement with the results from seismological studies (Miura et al. 2000). After the earthquake the volcano deformation ceased.

Pingue et al. (2003) describe how deformation monitoring is carried out in the Neapolitan volcanic area, Italy, which includes three active volcanoes. A permanent GPS network of 20 stations is combined with a levelling network consisting of 800 benchmarks, covering an area of about $500 \mathrm{~km}^{2}$. For example, the sub-network used to monitor Mt. Vesuvius consists of four permanent GPS stations operating at a 30s data rate (baselines are processed relative to the reference station located in Naples, $20 \mathrm{~km}$ away), as well as several sites that are observed periodically with GPS and a levelling network of about 300 benchmarks (Fig. 5). 


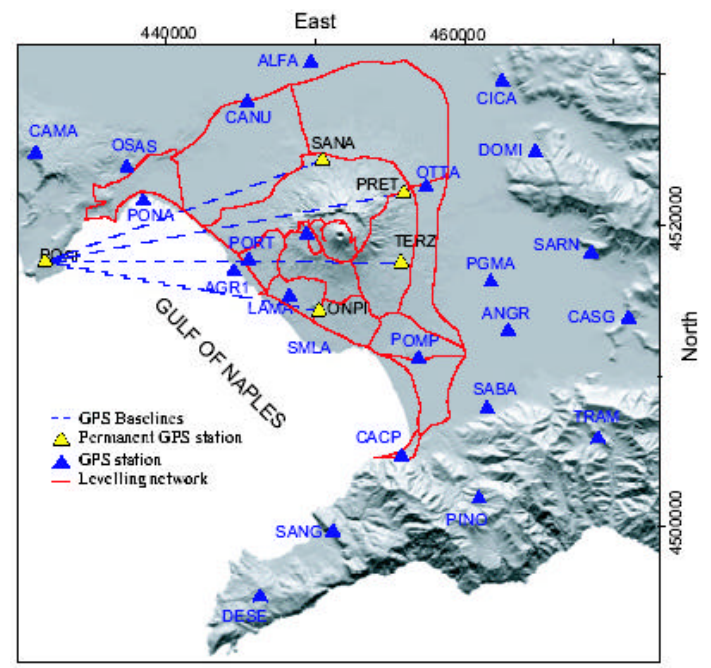

Figure 5. Monitoring network at Mt. Vesuvius, adapted from Pingue et al. (2003)

Recently a software package called Eolo has been developed in Italy, which permits the automatic management of data from a GPS deformation monitoring network (Amore et al. 2002). The software combines the treatment of raw data, their storage in a database, the calculation of the main strain parameters, and the visualisation of the results. Eolo takes into account a lot of the problems associated with the management of a deformation monitoring network. Missing data due to technical difficulties is dealt with by carrying out a daily database check for a period of time specified by the user, thus verifying the presence of new sessions from preceding days. If new data are found, the calculations are repeated using these new sessions. Unlike other software, the constant operation of a reference station is not required. If data are lacking from a station, the bases connected to it are excluded without affecting the network solution. In addition, Eolo is capable of contacting the supervisor by email or SMS messages over the mobile telephone network whenever any anomaly in the analysed data is detected. The desired parameters, such as height variation, distance variation, dilateration and shear, can be visualised in several panels for easy interpretation. Eolo is in use on the island of Stromboli, Italy where a network of four continuous GPS receivers monitors the volcano by observing a 3-hour session daily.

Small scale deformation monitoring networks imply a high density of GPS stations in order to achieve a sufficient resolution of the deformation pattern. However, these systems use expensive, dual-frequency GPS receivers, and this high expense can severely restrict the number of GPS stations that can be deployed. Usually daily baseline solutions are determined, although it is possible to process shorter sessions if the frequency of the data transfer from the remote stations to the computing facility, and the processing software package used, allow this. At the Kilauea volcano, efforts have been made to upgrade the continuous GPS network, so that instead of the routinely generated 24-hour solutions, 15-minute position estimates can be computed in near real-time, based on a random walk parameterisation of ground displacement. Using this approach, smaller inflation events that had amplitudes as low as 1cm, with periods ranging from 6 hours to 2 days, were observed (Larson et al. 2001).

\section{Continuous Kinematic GPS Networks}

The Real-Time Kinematic (RTK) GPS surveying technique typically requires two dual-frequency GPS receivers, connected by a radio data link. Carrier phase measurements are simultaneously observed at the reference or base station and the (user) rover station. The base station generates RTK messages and transmits these to the rover receiver. Using these corrections, the rover can potentially determine its position to centimetre accuracy in realtime, making this an excellent option for volcano deformation monitoring applications where baseline lengths are typically below $10-20 \mathrm{~km}$. Several GPS manufacturers have developed RTK products, which can be used for deformation monitoring.

One such system was modified to specifically meet the requirements of a volcano deformation monitoring application, and has been deployed at the Rabaul volcano in Papua New Guinea (Lowry \& MacLeod 1997). It works essentially as a reverse RTK system by computing the position solutions at the rover and then transmitting these results back to the base for archiving. While this approach delivers real-time positions of the monitoring stations, the requirements for hardware, software, field computer and telemetry components are relatively high, making the equipment comparatively expensive. The volume of data transmission between the base and rover is doubled, which either limits the number of GPS sites in the network, or the sampling rate between epochs, as only one station at a time can transmit its data to the base. 
Researchers in Germany developed the GPS-based Online Control and Alarm (GOCA) system, a software infrastructure that is designed to receive GPS baseline solutions from any combination of single- or dualfrequency GPS systems (Kälber et al. 2000). It can be set up as an early warning system to monitor engineering structures, landslide activity, earthquakes or volcanoes. Data from the base station is transmitted to the rover stations, where the baseline processing takes place. The estimated baseline vectors, along with their covariances and other information, are then transferred to the GOCA centre via radio modems. Here, a network adjustment is performed in order to detect any movements between observation epochs. The system is designed to handle both permanently and intermittently occupied rover stations, offering a high degree of flexibility. GOCA has since been employed for several deformation monitoring applications (GOCA 2006, Kälber \& Jäger 2001).

Geodetics, Inc. (2006) has developed and implemented a commercial wide-area network RTK system that provides precise, instantaneous (Epoch-by-Epoch ${ }^{\mathrm{TM}}$ ) positioning from multiple base stations, with a latency of about 1 second with existing wireless services. This system has been successfully used in several volcanic areas (Bock 2004).

Irwan et al. (2003) describe how (post-processed) kinematic GPS processing was used to successfully detect rapid ground deformation leading up to a submarine eruption of the Miyakejima volcano, Japan. The GPS network consisted of 12 stations and data were processed at a 30s rate in kinematic mode using the Bernese version 4.2 software (Rothacher \& Mervart 2001). A pseudo-kinematic coordinate estimation sequence was used, including (1) cycle-slip screening and outlier removal using the ionosphere-free linear combination (L3) double-difference phase residuals, (2) ambiguity resolution using wide-lane (L5) and then L3 single differences. A limiting factor is the number of unknown parameters, since a new set of coordinates is determined every epoch. To reduce the number of coordinate sets, after fixing L5 ambiguities, the estimated ambiguity is introduced in a subsequent solution where an observation window of 8 hours is used to obtain the epoch-byepoch coordinates.

Pugliano et al. (2004) report on a test carried out in the Neapolitan volcanic area, Italy, based on the use of an advanced post-mission multiple reference station RTK positioning method named MultiRefPM ${ }^{\mathrm{TM}}$. This system uses two-way communication and essentially operates in three steps. First, the errors at the reference stations are estimated using carrier-phase observations. Second, these errors are interpolated to the rover receiver location. In the third step the corrections are transmitted to the rover, usually by generating virtual reference station data that the rover can accept using a single reference station data format. By using multiple reference stations this methodology improves error modelling, resulting in higher accuracy compared to using only one reference station, and it appears to have high potential under actual real-time conditions.

RTK systems can provide real-time coordinates of rover stations at the computing facility and are certainly an attractive option for a range of deformation monitoring applications. However, such systems are comparatively expensive. On a volcano, most of the time deformational signals cannot be characterised as truly 'kinematic', except under extreme conditions just before an eruption. Generally only positions are received and stored by the base facility, hence raw GPS data are not archived for the processing of longer observation sessions. This, however, may be very useful in order to analyse long-term displacements and to check the RTK solution in quiescent periods.

\section{Low-Cost GPS Networks}

The monitoring systems mentioned above are very costly because they require the use of high-quality, dualfrequency instrumentation. This is a significant constraint, especially as most of the world's active volcanoes are located in less developed countries, which cannot fund such systems for monitoring all potentially hazardous volcanoes. In recent years, however, low-cost options have been developed. Based on original equipment manufacturer (OEM) board sets, single-frequency GPS receivers are available at a fraction of the cost of standard dual-frequency receivers. They can be integrated into custom-built systems that output code and/or carrier phase measurements for baseline determination.

The lower cost of such systems means that it is possible to deploy a denser network, which in turn makes it feasible to map deformation on a finer scale. Such systems can fulfil all requirements needed for a deformation monitoring system, such as suitability for remote locations, power supply in the form of batteries and solar panels, transmission of data via radio links, and computerised control of data management and communications software. In addition, the lack of peripheral components to the GPS receiver and computer (e.g. displays, screens and hard disks) significantly reduces the power usage of the system. Hence, the size of the battery bank and the solar panels can be reduced, resulting in further cost savings.

The GPS volcano deformation monitoring system developed by the University NAVSTAR Consortium (UNAVCO) is an example of such a system. As described by Meertens et al. (1999), single-frequency GPS 
receivers continuously transmit carrier phase and pseudo-range observations through a Time Delay Multiple Access (TDMA) radio data modem network to a central computing facility. Instead of sending logged data files, these 'intelligent' radios send GPS data epochs continuously according to pre-defined time slots. The data can be processed at hourly or shorter intervals in order to provide station deformation estimates. The UNAVCO system was first tested at the Long Valley Caldera, California, in 1998 and has subsequently been deployed on several other volcanoes, including Popocatepetl, Mexico (Cabral-Cano et al. 1999), Kilauea/Mauna Loa, Hawaii (Cervelli et al. 2002) and Taal volcano, Philippines (Bartel et al. 2003). The latter network comprises 11 remote stations located on the flanks of the volcano (Fig. 6) in addition to three continuously operating dual-frequency GPS receivers that had been deployed earlier (Lowry et al. 2001), making it one of the densest volcano monitoring networks in the world. Using daily coordinate solutions and the Bernese version 4.2 software (Rothacher \& Mervart 2001), this network revealed distinct periods of inflation and deflation with the largest uplift being approximately $12 \mathrm{~cm}$ (Bartel et al. 2003). As expected, the precision of the height component decreases approximately linearly with increasing baseline length, in this case from $\pm 5 \mathrm{~mm}$ at $2.8 \mathrm{~km}$ to $\pm 18 \mathrm{~mm}$ at $13.3 \mathrm{~km}$.

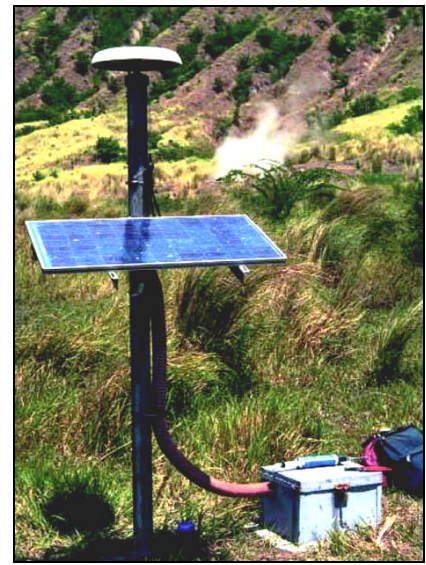

Figure 6. L1 GPS station on Taal volcano (Bartel et al. 2003)

Rizos et al. (2000) and Roberts (2002) describe the prototype of a four-station network of single-frequency GPS receivers installed on Mt. Papandayan, Indonesia. The network array consists of one base station situated at the foot of the volcano and three 'slave' stations located approximately $8 \mathrm{~km}$ away in the zone of deformation around the crater of the volcano. Each station comprises five components: GPS/PC module, radio modem sub-system, monument, GPS antenna, and power supply (Fig. 7).

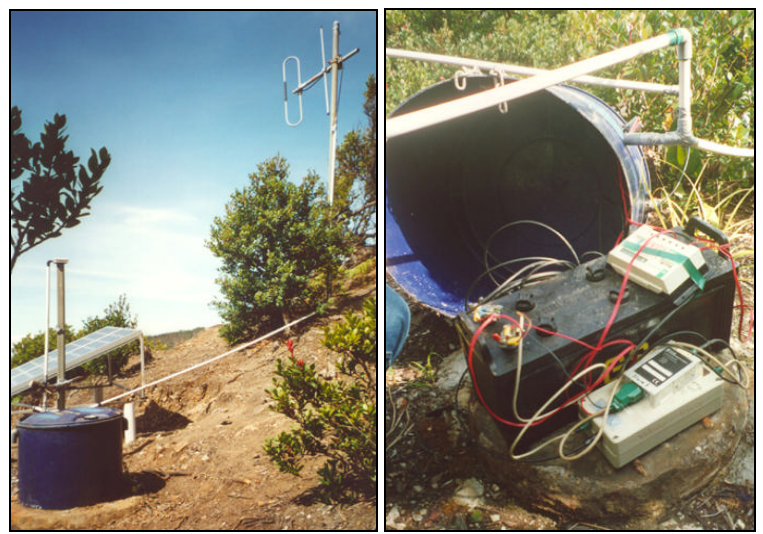

Figure 7. Slave station setup on Mt. Papandayan (Janssen 2003)

Data are collected at a sampling rate of 15 seconds. All software to operate this GPS network has been custom designed to ensure maximum design flexibility. Rudimentary software onboard the GPS/PC module controls the creation of a new data file every hour, which is stored in the RAM at the slave station, and controls the radio transmission of the completed sessions to the base station. The communications software at the base station is more 'intelligent' than that at the slave stations and controls the data download via the radio modems by polling each slave station in sequence on an hourly basis. The data received is then automatically converted to the Receiver INdependent EXchange (RINEX) format and stored on the hard disk at the base facility. Although currently not implemented, the system has the potential for automatic data processing at the base facility with minimum delay. The second generation of this single-frequency system includes improvements in hardware and software, resulting in a more robust system. Preliminary tests have shown that, using a minimum of approximately 30 minutes of data with a sampling rate of $5 \mathrm{~s}$, the computed baselines are accurate to $5 \mathrm{ppm}$ for 
baseline lengths less than about $7 \mathrm{~km}$ (Roberts et al. 2004). Ionospheric bias cannot be accounted for because single frequency receivers are employed.

If funding is limited, low-cost systems are an attractive alternative for volcano deformation monitoring. In general, a single-frequency, carrier phase-tracking system is appropriate for small-scale continuous GPS networks if the baseline lengths are not longer than about $10 \mathrm{~km}$ (a scale usually adopted for volcano deformation monitoring systems). This 'rule-of-thumb' implies that the differential ionospheric delay between the two receivers is assumed to be essentially zero, and therefore does not impact on the baseline result. Orbit bias over such short distances can also be ignored (Rizos 1997). However, these assumptions do not always hold true, and a sparse outer network of dual-frequency receivers may be required to ensure high accuracy (Janssen et al. 2002).

During the past few years a methodology has been developed for utilising data collected by mixed sets of singlefrequency and dual-frequency GPS receivers (Brunner et al. 2000, Janssen \& Rizos 2003). A sparse dualfrequency network surrounding the deformation zone of the volcano is used to generate empirical 'correction terms', which are then applied to the inner single-frequency data during baseline processing. Such a mixed-mode GPS network approach can account for the ionospheric biases that would normally be neglected in a system using single-frequency instrumentation only. Janssen (2003) applied this methodology to the aforementioned GPS volcano deformation monitoring network on Mt. Papandayan and showed its potential to achieve cm-level accuracy for an epoch-by-epoch solution. This approach offers considerable cost savings for deformation monitoring applications, which require a dense spatial coverage of GPS stations, and where it is not feasible to establish permanent GPS networks using expensive dual-frequency instrumentation. If the dual-frequency sites are appropriately chosen, it is possible to use one such fiducial network to simultaneously generate 'corrections' for a number of different volcanoes within the network. Furthermore, the ever-increasing number of permanent dual-frequency GPS networks established around the world could provide such infrastructure at virtually no extra cost.

For baselines involving a significant difference in station altitude, which is often the case in GPS volcano deformation monitoring networks, the accuracy can be further improved by estimating an additional residual relative zenith delay parameter to correctly account for the tropospheric bias. Among others, Abidin et al. (1998) and Roberts \& Rizos (2001) state that global troposphere models alone are not sufficient in this case and the relative tropospheric delay needs to be estimated and corrected.

\section{PROCESSING STRATEGIES}

Depending on the type of movement expected in a deformation monitoring application, different data processing strategies can be used. If 'slow' deformation at a constant rate is expected (e.g. tectonic plate movement or ground subsidence), the data are usually processed in static sessions of a few hours to a few days in length, assuming no movement during the session. This is generally done in post-processing mode, as the deformation does not pose an imminent threat to surrounding structures or the population inhabiting the area. In this case parameters describing precise satellite orbits and full earth rotation parameters, which are generally not available in real-time, can be used to improve the quality of the solution. This procedure is typically used for processing large scale, global networks in order to detect plate motions where a comparison of several campaigns is usually sufficient to derive the average rate of tectonic motion. However, if the deformational signal is expected to take place over a short period of time ('sudden' deformation, e.g. caused by earthquakes) and/or varies with time ('fast' continuous deformation, e.g. long suspension bridges), the sampling interval must be increased accordingly. This suggests the use of continuous GPS networks, using short static sessions, or epoch-by-epoch solutions (resembling a kinematic processing strategy). If the deformation can cause failure of the deforming body (e.g. a collapsing dam, or an erupting volcano), a (near) real-time, epoch-by-epoch solution is desired in order to detect the deformation as soon as it occurs, so as to initiate warning and evacuation procedures.

In the case of volcano monitoring the deformation is expected to be of a mixed nature. During periods of quiescence the deformation will be slow (or not present at all), while increased activity will cause ground movements of increasing magnitude due to magma intrusion in the hours to days prior to an eruption. Hence, a near real-time, epoch-by-epoch solution is preferred in order to detect movements on the flanks of a volcano over a relatively short period of time. This can be interpreted as a 'slow kinematic' approach, where a static receiver moves slowly but continuously due to ground surface movement. In contrast to a true RTK system where only coordinate positions are stored and analysed, the raw GPS data are also being archived. Hence the raw data can be post-processed in longer observation sessions in order to detect long-term deformational signals and to periodically connect the sites to the International Terrestrial Reference Frame (ITRF) through the IGS network. A fully automated system would then be able to 'switch' between epoch-by-epoch processing and hourly or daily solutions, depending on the nature of the deformation. 


\section{CONCLUDING REMARKS}

Ground deformation of a volcano is considered a sure indicator of impending eruptive activity. GPS is ideally suited for detecting and monitoring such deformation, thus contributing to hazard mitigation. In order to detect ground movement as it occurs, it is necessary to employ continuously operating GPS networks which can be managed in static or kinematic mode. Daily to hourly processing of dual-frequency static networks achieves high-quality coordinate solutions and is suitable for quiescent volcanoes. In periods of high activity, however, even hourly observation sessions can be too long to truly identify the dynamics of the volcano. In this case, a kinematic approach is preferred in order to generate epoch-by-epoch solutions in (near) real-time. The major disadvantage of these systems is their high cost, especially in case of more complex volcanoes where a large number of GPS stations is required. Considering also that most of the world's volcanoes are located in less developed countries with limited funding capabilities and that sites are likely to be damaged during eruptive activity, a low-cost option is desired. The utilisation of single-frequency instrumentation provides such a lowcost alternative and has successfully been applied to several volcanoes. However, the main problem faced in the quest for providing reliable, high-accuracy results is the ionospheric bias which cannot be accounted for when using only one GPS frequency. The ionospheric disturbances are highly pronounced in the equatorial region (where most active volcanoes are situated) and particularly severe during maximum periods of the 11-year solar cycle. Therefore, a mixed-mode GPS network approach presents itself as an excellent solution since it combines low-cost single frequency instrumentation with a small number of dual-frequency GPS receivers in order to account for the ionospheric bias.

A combination of GPS data with observations from GLONASS and, in the near future, Galileo satellites can improve the volume of observations and the satellite geometry. Subsequently the reliability of the baseline results can be enhanced, especially for receivers located at the flanks of the volcano where the deforming body itself blocks out part of the sky. Obviously, the challenge lies in combining observations from different satellite systems (and their respective 'correction terms') in order to generate one baseline solution.

The ideal GPS volcano deformation monitoring system simultaneously satisfies the criteria of high accuracy, low-cost, continuous measurements with real-time data access and full automation. However, in practice the realisation of such a system is usually a compromise due to many factors, including logistics, funding, accessibility, magnitude and frequency of expected movements, data handling, power supply and communications. Integration of such a GPS system with other geodetic techniques is required in order to build a volcano deformation monitoring system that can thoroughly determine the dynamics of the volcano, thereby enhancing short-term assessments of hazards and potentially extending the warning time before hazardous eruptions. This can be accomplished by combining the use of episodic techniques (campaign-style GPS, levelling, EDM and InSAR) to achieve optimal precision and spatial resolution over the broader volcano area with continuous sensors (continuous GPS, tiltmeters and strain meters) to achieve the desired temporal resolution.

\section{REFERENCES}

Abidin, H.Z. (1998) Monitoring the volcano deformation using repeated GPS surveys: Experiences and plans, Proc. Int. Workshop on Advances in GPS Deformation Monitoring, Perth, Australia, 24-25 September, paper 18, 27pp.

Abidin, H.Z., Meilano, I., Suganda, O.K., Kusuma, M.A., Muhardi, D., Yolanda, O., Setyadji, B., Sukhyar, R., Kahar, J. and Tanaka, T. (1998) Monitoring the deformation of Guntur volcano using repeated GPS survey method, Proc. XXI Int. Congress of FIG, Commission 5: Positioning and Measurements, Brighton, UK, 1925 July, pp. 153-169.

Abidin, H.Z., Andreas, H., Gamal, M., Hendrasto, M., Suganda, O.K., Purbawinata, M.A., Meilano, I. and Kimata, F. (2004) The deformation of Bromo volcano as detected by GPS surveys method, Proc. Int. Symp. on GNSS/GPS (GNSS2004), Sydney, Australia, 6-8 December, 11pp.

Abidin, H.Z., Andreas, H., Gamal, M., Suganda, O.K., Meilano, I., Hendrasto, M., Kusuma, M.A., Darmawan, D., Purbawinata, M.A., Wirakusumah, A.D. and Kimata, F. (2006) Ground deformation of Papandayan volcano before, during, and after the 2002 eruption as detected by GPS surveys, GPS Solutions, vol. 10, pp. 75-84.

Amelung, F., Jonsson, S., Zebker, H. and Segall, P. (2000) Widespread uplift and 'trapdoor' faulting on Galapagos volcanoes observed with radar interferometry, Nature, vol. 407, pp. 993-996.

Amore, M., Bonaccorso, A., Ferrari, F. and Mattia, M. (2002) Eolo: Software for the automatic on-line treatment and analysis of GPS data for environmental monitoring, Computers \& Geosciences, vol. 28, pp. 271-280.

Bartel, B.A., Hamburger, M.W., Meertens, C.M., Lowry, A.R. and Corpuz, E. (2003) Dynamics of active magmatic and hydrothermal systems at Taal volcano, Philippines, from continuous GPS measurements, $J$. Geophys. Res., vol. 108, no. B10, 2475, doi:10.1029/2002JB002194. 
BGVN (1991) Unzen (Kyushu), Bulletin of the Global Volcanism Network, vol. 16, no. 5, available from http://www.volcano.si.edu/reports/bulletin/contents.cfm?issue=1605 (last accessed December 2006).

Blick, G.H., Otway, P.M. and Scott, B.J. (1989) Deformation monitoring of Mt. Erebus, Antarctica, 1980-1985, in: Latter, J.H. (Ed.) Volcanic Hazards: Assessment and Monitoring, Springer-Verlag, Berlin-New York, pp. 554-560.

Bock, Y. (2004) Instantaneous network RTK positioning in regions of active deformation, Proc. ION GNSS 2004, Long Beach, CA, 21-24 September, available from http://www.geodetics.com/WebSite/news.html (last accessed December 2006).

Bonasia, V. and Pingue, F. (1981) Ground deformations on Mt. Vesuvius from 1977 to 1981, Bull. Volcanol., vol. 44, pp. 513-520.

Briole, P., Massonnet, D. and Delacourt, C. (1997) Post-eruptive deformation associated with the $1986-87$ and 1989 lava flows of Etna detected by radar interferometry, Geophys. Res. Lett., vol. 24, no. 1, pp. 37-40.

Brunner, F.K., Hartinger, H. and Richter, B. (2000) Continuous monitoring of landslides using GPS: A progress report, in: Bauer, S.J. and Weber, F. (Eds.): Proceedings Geophysical Aspects of Mass Movement, Austrian Academy of Sciences, Vienna, pp. 75-88.

Cabral-Cano, E., Dixon, T., Meertens, C. and Correa-Mora, F. (1999) Surface deformation on active volcanoes in central Mexico, paper pres. at 1999 UNAVCO Volcano Geodesy Workshop, Jackson Hole, WY,16-18 September.

Cervelli, P., Segall, P., Amelung, F., Garbeil, H., Meertens, C., Owen, S., Miklius, A. and Lisowski, M. (2002) The 12 September 1999 upper east rift zone dike intrusion at Kilauea volcano, Hawaii, J. Geophys. Res., vol. 107, no. B7, 2150, doi:10.1029/2001JB000602.

Dixon, T.H., Mao, A., Bursik, M., Heflin, M., Langbein, J., Stein, R. and Webb, F. (1997) Continuous monitoring of surface deformation at Long Valley Caldera, California, with GPS, J. Geophys. Res., vol. 102, no. B6, pp. 12017-12034.

Dvorak, J. and Dzurisin, D. (1997) Volcano geodesy: The search for magma reservoirs and the formation of eruptive vents, Rev. Geophys., vol. 35, no. 3, pp. 343-384.

Ewert, J.W. and Swanson, D.A. (Eds.) (1992) United States Geological Survey Bulletin 1966, Monitoring Volcanoes: Techniques and Strategies Used by Staff of the Cascades Volcano Observatory 1980-90, United States Government Printing Office, Washington DC.

Foulger, G.R., Bilham, R., Morgan, J. and Einarsson, P. (1987) The Iceland geodetic field campaign 1986, Eos, vol. 68 , pp. 1801-1818.

Furuya, M. (2004) Localized deformation at Miyakejima volcano based on JERS-1 radar interferometry: 19921998, Geophys. Res. Lett., vol. 31, L05605, doi:10.1029/2003GL019364.

Geodetics, Inc. (2006) http://www.geodetics.com (last accessed December 2006).

GOCA (2006) http://www.goca.info/index_e.html (last accessed December 2006).

Irwan, M., Kimata, F., Fujii, N., Nakao, S., Watanabe, H., Sakai, S., Ukawa, M., Fujita, E. and Kawai, K. (2003) Rapid ground deformation of the Miyakejima volcano on 26-27 June 2000 detected by kinematic GPS analysis, Earth Planets Space, vol. 55, pp. e13-e16.

Janssen, V. (2003) A Mixed-Mode GPS Network Processing Approach for Volcano Deformation Monitoring, PhD Dissertation, UNISURV S-74, School of Surveying and Spatial Information Systems, The University of New South Wales, Sydney, Australia.

Janssen, V. and Rizos, C. (2003) Processing mixed-mode GPS networks for deformation monitoring applications, zfv - Zeitschrift für Geodäsie, Geoinformation und Landmanagement, vol. 128, no. 2, pp. 8796.

Janssen, V., Roberts, C., Rizos, C. and Abidin, H.Z. (2002) Low-cost GPS-based volcano deformation monitoring at Mt. Papandayan, Indonesia, J. Volcanol. Geotherm. Res., vol. 115, no. 1-2, pp. 139-151.

Kälber, S. and Jäger, R. (2001) GPS-based online control and alarm system (GOCA), Proc. 10 ${ }^{\text {th }}$ FIG Int. Symp. on Deformation Measurements, Orange, CA, 19-22 March, pp. 164-174.

Kälber, S., Jäger, R. and Schwäble, R. (2000) A GPS-based online control and alarm system, GPS Solutions, vol. 3, no. 3, pp. 18-25.

King, R.W. and Bock, Y. (1995) Documentation of the GAMIT GPS Analysis Software Version 9.3, Massachusetts Institute of Technology, Cambridge.

Larson, K.M., Cervelli, P., Lisowski, M., Miklius, A., Segall, P. and Owen, S. (2001) Volcano monitoring using the Global Positioning System: Filtering strategies, J. Geophys. Res., vol. 106, no. B9, pp. 19453-19464.

Lowry, A. and MacLeod, R. (1997) PMoS - A real time precise DGPS continuous deformation monitoring system, Proc. ION GPS-97, Kansas City, MO, 16-19 September, pp. 923-927.

Lowry, A.R., Hamburger, M.W., Meertens, C.M. and Ramos, E.G. (2001) GPS monitoring of crustal deformation at Taal volcano, Philippines, J. Volcanol. Geotherm. Res., vol. 105, pp. 35-47.

Lu, Z., Fatland, R., Wyss, M., Li, S., Eichelberger, J., Dean, K. and Freymueller, J. (1997) Deformation of New Trident volcano measured by ERS-1 SAR interferometry, Katmai National Park, Alaska, Geophys. Res. Lett., vol. 24, no. 6, pp. 695-698. 
Lu, Z., Masterlark, T., Dzurisin, D., Rykhus, R. and Wicks Jr., C. (2003) Magma supply dynamics at Westdahl volcano, Alaska, modeled from satellite radar interferometry, J. Geophys. Res., vol. 108, no. B7, 2354, doi:10.1029/2002JB002311.

Marshall, G.A., Langbein, J., Stein, R.S., Lisowski, M. and Svarc, J. (1997) Inflation of Long Valley Caldera, California, basin and range strain, and possible Mono Craters dike opening from 1990-94 GPS surveys, Geophys. Res. Lett., vol. 24, no. 9, pp. 1003-1006.

Matsushima, T. and Takagi, A. (2000) GPS and EDM monitoring of Unzen volcano ground deformation, Earth Planets Space, vol. 52, pp. 1015-1018.

Mattioli, G.S., Dixon, T.H., Farina, F., Howell, E.S., Jansma, P.E. and Smith, A.L. (1998) GPS measurement of surface deformation around Soufriere Hills volcano, Montserrat, from October 1995 to July 1996, Geophys. Res. Lett., vol. 25, no. 18, pp. 3417-3420.

Meertens, C.M., Braun, J., Mencin, D., Conquest, C. and Estey, L. (1999) Development of a low-cost singlefrequency GPS system for volcano deformation monitoring, paper pres. at 1999 UNAVCO Volcano Geodesy Workshop, Jackson Hole, WY, 16-18 September.

Miura, S., Ueki, S., Sato, T., Tachibana, K. and Hamaguchi, H. (2000) Crustal deformation associated with the 1998 seismo-volcanic crisis of Iwate volcano, Northeastern Japan, as observed by a dense GPS network, Earth Planets Space, vol. 52, no. 11, pp. 1003-1008.

Mogi, K. (1958) Relations between the eruptions of various volcanoes and the deformation of the ground surface around them, Bull. Earthquake Res. Inst. Univ. Tokyo, vol. 36, pp. 99-134.

Newhall, C.G. and Punongbayan, R.S. (Eds.) (1996) Fire and Mud: Eruptions and Lahars of Mount Pinatubo, Philippines, University of Washington Press, Seattle.

Nishi, K., Ono, H. and Mori, H. (1999) Global Positioning System measurements of ground deformation caused by magma intrusion and lava discharge: The 1990-1995 eruption at Unzendake volcano, Kyushu, Japan, J. Volcanol. Geotherm. Res., vol. 89, pp. 23-34.

Nunnari, G. and Puglisi, G. (1994) The Global Positioning System as a useful technique for measuring ground deformations in volcanic areas, J. Volcanol. Geotherm. Res., vol. 61, pp. 267-280.

Omori, F. (1914) The Sakura-jima eruptions and earthquakes, Bulletin of the Imperial Earthquake Investigation Committee 8, nos 1-6, pp. 525.

Owen, S., Segall, P., Lisowski, M., Miklius, A., Denlinger, R. and Sako, M. (2000a) Rapid deformation of Kilauea volcano: Global Positioning System measurements between 1990 and 1996, J. Geophys. Res., vol. 105, no. B8, pp. 18983-18998.

Owen, S., Segall, P., Lisowski, M., Miklius, A., Murray, M., Bevis, M. and Foster, J. (2000b) January 30, 1997 eruptive event on Kilauea volcano, Hawaii, as monitored by continuous GPS, Geophys. Res. Lett., vol. 27, no. 17 , pp. $2757-2760$.

Pingue, F., Del Gaudio, C., De Natale, G., Obrizzo, F., Sepe, V., Cecere, G., De Martino, P., Malaspina, S., Serio, C., Siniscalchi, V. and Tammaro, U. (2003) Monitoring and deformation analysis in Neapolitan Volcanic Area (Southern Italy), Proc. $11^{\text {th }}$ FIG Int. Symp. on Deformation Measurements, Santorini, Greece, 25-28 May, 105-116.

Puglisi, J., Bonforte, A. and Maugeri, S.R. (2001) Ground deformation patterns on Mount Etna, 1992 to 1994 , inferred from GPS data, Bull. Volcanol., vol. 62, pp. 371-384.

Pugliano, G., Obrizzo, F., Pingue, F., Sepe, V., Alves, P. and Lachapelle, G. (2004) Monitoring the Neapolitan Volcanic Area using an advanced multiple reference station RTK DGPS technique, Proc. ION GNSS 2004, Long Beach, CA, 21-24 September, pp. 1703-1712.

Rizos, C. (1997) Principles and Practice of GPS Surveying, Monograph 17, School of Geomatic Engineering, The University of New South Wales, Sydney, Australia, 555pp.

Rizos, C., Han, S., Roberts, C., Han, X., Abidin, H.Z., Suganda, O.K. and Wirakusumah, A.D. (2000) Continuously operating GPS-based volcano deformation monitoring in Indonesia: The technical and logistical challenges, in: Schwarz, K.-P. (Ed.) Geodesy Beyond 2000: The Challenges of the First Decade, Proc. IAG General Assembly, Birmingham, UK, 19-30 July 1999, Springer-Verlag, pp. 361-366.

Roberts, C. (2002) A Continuous Low-Cost GPS-Based Volcano Deformation Monitoring System in Indonesia, PhD Dissertation, UNISURV S-73, School of Surveying and Spatial Information Systems, The University of New South Wales, Sydney, Australia.

Roberts, C. and Rizos, C. (2001) Mitigating differential troposphere effects for GPS-based volcano monitoring, Proc. $5^{\text {th }}$ Int. Symp. on Satellite Navigation Technology \& Applications (SatNav), Canberra, Australia, 24-27 July, paper 38, 10pp.

Roberts, C.A., Seynat, C., Rizos, C. and Hooper, G. (2004) Low-cost deformation measurement for volcano monitoring, $3^{\text {rd }}$ FIG Regional Conference "Surveying the Future - Contributions to Economic, Environmental and Social Development", Jakarta, Indonesia, 3-7 October, paper TS19.2, available from http://www.fig.net/pub/jakarta/programme.htm (last accessed December 2006).

Rosen, P.A., Hensley, S., Zebker, H.A., Webb, F.H. and Fielding, E.J. (1996) Surface deformation and coherence measurements of Kilauea volcano, Hawaii, from SIR-C radar interferometry, J. Geophys. Res., vol. 101, pp. 23109-23125. 
Rothacher, M. and Mervart, L. (2001) Bernese GPS Software Version 4.2, Astronomical Institute, University of Berne, Switzerland.

Shepherd, J.B., Herd, R.A., Jackson, P. and Watts, R. (1998) Ground deformation measurements at the Sourfriere Hills volcano, Montserrat: II: Rapid static GPS measurements June 1996 - June 1997, Geophys. Res. Lett., vol. 25, no. 18, pp. 3413-3416.

Shimada, S., Fujinawa, Y., Sekiguchi, S., Ohmi, S., Eguchi, T. and Okada, Y. (1990) Detection of a volcanic fracture opening in Japan using Global Positioning System measurements, Nature, vol. 343, pp. 631-633.

Sigmundsson, F., Einarsson, P. and Bilham, R. (1992) Magma chamber deflation recorded by the Global Positioning System: The Hekla 1991 eruption, Geophys. Res. Lett., vol. 19, no. 14, pp. 1483-1486.

Suganda, O.K. (1993) Analysis of EDM Data in Association with the 1992 Eruption at Merapi Volcano, Indonesia, Masters Thesis, Department of Geophysics, Kyoto University, Japan.

Swanson, D., Casadevall, T.J., Dzurisin, D., Malone, S.D., Newhall, C.G. and Weaver, C.S. (1983) Predicting eruptions at Mount St. Helens, June 1980 through December 1982, Science, vol. 221, pp. 1369-1376.

USGS (2006a): http://vulcan.wr.usgs.gov/Projects/Augustine/augustine_monitoring_intro.html (last accessed December 2006).

USGS (2006b): http://volcanoes.usgs.gov/About/What/Monitor/Deformation/GPSKilauea.html (last accessed December 2006). 